This item was submitted to Loughborough's Research Repository by the author.

Items in Figshare are protected by copyright, with all rights reserved, unless otherwise indicated.

\title{
Non-contact laser sealing of thin polyester food packaging films
}

PLEASE CITE THE PUBLISHED VERSION

http://dx.doi.org/10.1016/j.optlaseng.2012.04.001

PUBLISHER

(c) Elsevier

VERSION

AM (Accepted Manuscript)

LICENCE

CC BY-NC-ND 4.0

REPOSITORY RECORD

Brown, Neil, David Kerr, Robert M. Parkin, Michael R. Jackson, and Fangmin Shi. 2019. "Non-contact Laser Sealing of Thin Polyester Food Packaging Films". figshare. https://hdl.handle.net/2134/13167. 
This item was submitted to Loughborough's Institutional Repository (https://dspace.lboro.ac.uk/) by the author and is made available under the following Creative Commons Licence conditions.

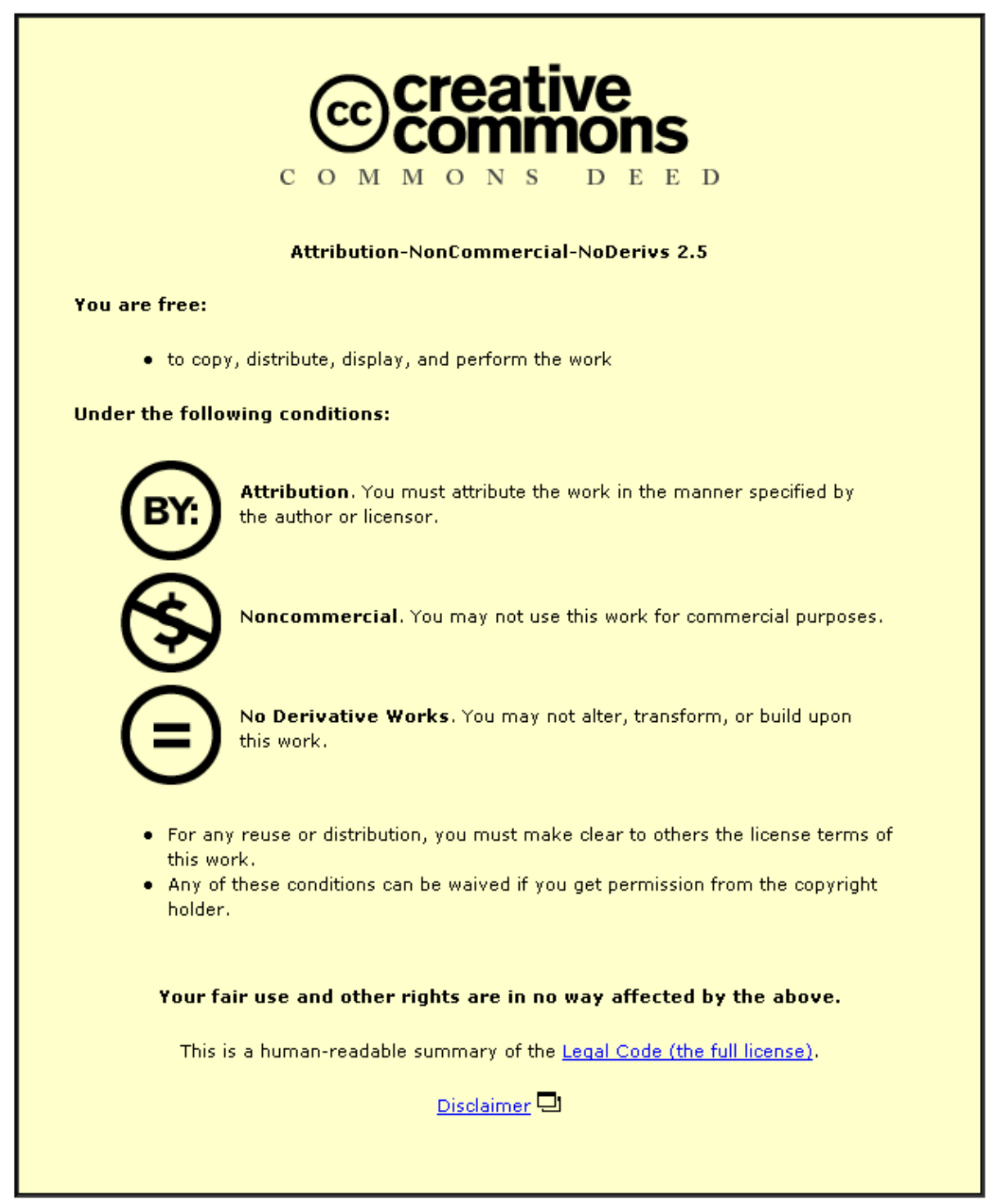

For the full text of this licence, please go to: http://creativecommons.org/licenses/by-nc-nd/2.5/ 


\section{Non-contact Laser Sealing of Thin Polyester Food Packaging Films}

Neil Brown ${ }^{1}$, David Kerr ${ }^{*}$, Robert M. Parkin, Michael R. Jackson and Fangmin Shi ${ }^{2}$

Mechatronics Research Group, Wolfson School of Mechanical and Manufacturing Engineering, Loughborough University LE11 3TU, U.K.

*Corresponding author: d.kerr@lboro.ac.uk, tel: +44 1509 227559, fax +44 1509227648

${ }^{1}$ Present address: IESD, Queens Building, DeMontfort University, Leicester, LE1 9BH, UK

${ }^{2}$ Present address: Applied Vision Research Centre, Loughborough University, LE11 3TU, U.K.

\section{Abstract}

We describe a laser-based, non-contact sealing technique for thin, polyester-based lidding films, used in PET containers for food packaging. The method uses a beam-steered laser to seal the container, thereby enabling virtually instant changeover from one product line to another. Unlike conventional sealing PET film processes, no bespoke tooling is required to hold the package components in close proximity and under pressure whilst the seal is formed. This greatly reduces sealing machine tooling costs and potential downtime at product changeovers. Results are presented that show that the process is able to produce seals of higher strength using thin $(26 \mu \mathrm{m})$ polyester film than those from the conventional thermal/mechanical process. This provides a potential for increased production flexibility, reduction in product wastage, and for reducing the cost and embodied energy in construction of a less massive sealing machine.

\section{Keywords}

Laser; Welding; Packaging; Polymer; Films; Food

\section{Abbreviations}

PET:

Polyethylene Terephthalate

PP:

Polypropylene

PE:

Polyethylene

MAP:

Modified Atmosphere Packaging 


\section{Introduction}

The packaging industry has been an important area for the development of thermoplastic materials as it has to deal with some very stringent requirements, such as mechanical strength, safety, longevity, sterility and aesthetic appearance. Most thermoplastic packaging

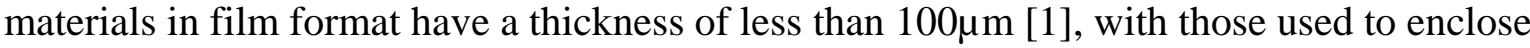
or to seal food containers being among the thinnest. Conventional food package sealing machinery relies on a heated platen or die, contained within the sealing head, which is pressed onto the film to provide a heat seal to the food container. Containers are held in a specially designed tooling jig, to enable the heated platen to align precisely with the periphery of the container. The internal parts of a typical heat sealing machine are shown in figure 1 , where the sealing head can be seen at the top right of the picture. Of note are that non-ferrous or rustproof parts are used since the machinery is frequently hosed down, the restricted amount of space available in and around the conveyor, including with regard to difficulty in manual changeover for tooling, and the debris that often accumulates beneath it. Also the relatively massive construction of the sealing head and support stanchions shows increased expense and embodied energy in the machine construction.

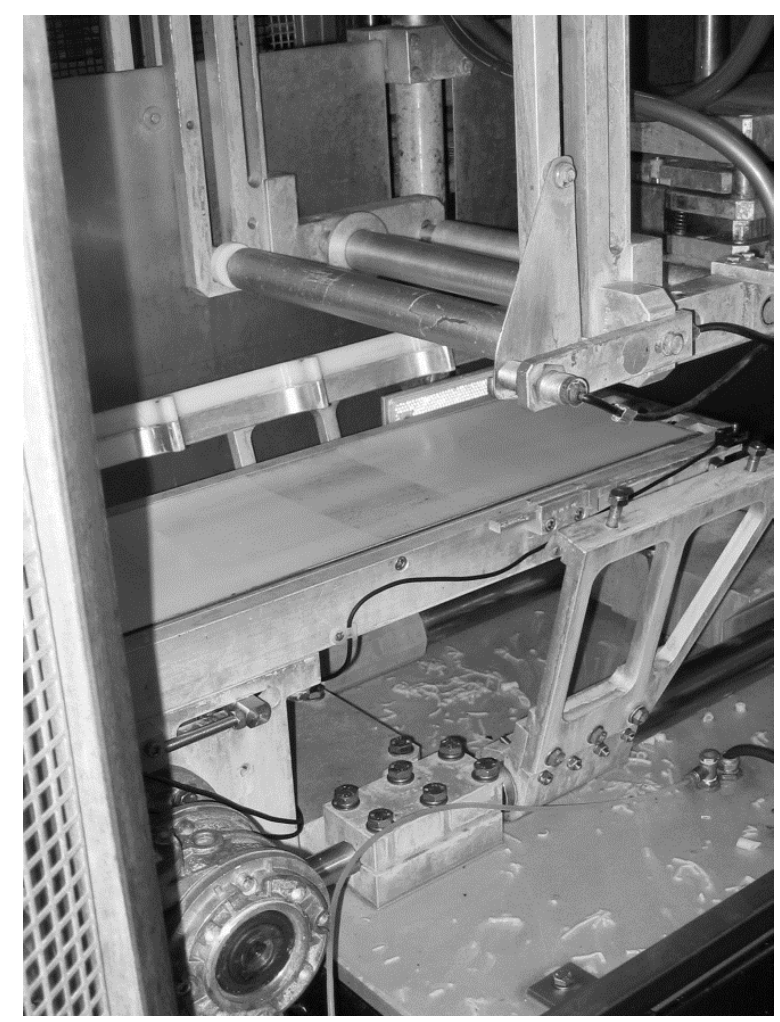

Fig. 1 Conventional package sealing machinery - the sealing head can be seen at the top right of the picture, conveyor and transfer arms towards the centre. 
Inside the conventional sealing head there are also thermocouples for temperature control and blades for trimming the film around the container. These parts, and heater coils, require constant cleaning and periodic replacement. Such specialised tooling is expensive and a different set is required for each container shape. A typical food producer may require capacity for ten or more such shapes. The intention of this work was to remove the need for the heated sealing head, high contact pressure, and blade cutters and transfer arms and to replace them with a scanning laser system that is capable of sealing any size or shape of container. The new process was designed to simply drape the film, under slight tension to keep it flat, across the containers to be sealed, allowing the laser beam to be scanned over virtually any 2-dimensional shape of container periphery to form the seal.

Welding of thermoplastics using laser transmission methods is today a well-established practice in many industries [1-3]. Low power scanning laser systems are relatively inexpensive in comparison to several sets of conventional tooling and would be capable of processing a very wide range of container designs, both for sealing and cutting away of the excess film. For very large or for some popular multi-compartment products, the laser power and duty cycle could be automatically adjusted for package designs with a significantly longer seal path. Set-up times between production runs would be virtually eliminated, as would spillages and machinery jams due to the present need for moving containers in and out of the seal tooling. The cost of running the machine would be reduced and tooling maintenance and storage costs would be virtually eliminated. Whilst wall-plug efficiencies need be factored into any detailed life cycle analysis, there would also be a potential to reduce standby loads in comparison to those in conventional "hot" tooling.

Premium cook/chill or oven-ready meals are typically low-volume, fast demand products which would benefit from the increased flexibility and greatly reduced line down-times inherent in a tooling-free sealing system. The food packaging industry has a general preference for a peelable package, whereby a smooth, even peel is produced that does not require excessive force. This helps to ensure, for example, that customers do not spill hot package contents when peeling.

In order to build a contactless sealing system for such products, a pilot study [4] was carried out to assess the feasibility of the laser sealing process on food-grade packaging materials. A major follow-on research programme was then undertaken to develop the laser sealing 
technology, where effective sealing using multi-layer, polypropylene barrier films and containers was demonstrated $[5,6]$. The work described in this paper focuses on laser sealing of the much thinner $(26 \mu \mathrm{m})$ polyester films used in short shelf-life, cook-chill product lines using CPET/APET trays. Such materials are much more difficult to seal using conventional laser transmission methods, due to the very low film thickness.

In normal overlap laser transmission welding of polymers, the laser beam heats the lower substrate which in turn transfers heat to the upper, laser transparent layer [7, 8]. A mutual melting pool then solidifies on cooling to create the joint. Considerable mechanical pressure is normally required to keep the contact faces of the materials close together whilst the weld is formed. However, for our laser sealing method using proprietary food lidding films such as “Esterpeel," [9] there is no applied pressure and no state change of the materials. Instead, the film has a very thin coating of adhesive material on its underside (in contact with the tray substrate). This layer is warmed by absorbing energy from the beam and sticks or seals to the warm tray surface. Seal conditions for Esterpeel are quoted by the manufacturer to be at around $140-210^{\circ} \mathrm{C}$, whilst the film only starts to soften at above $218^{\circ} \mathrm{C}$. In this work, we make the distinction between sealing (in the case of the films just described) and welding, where both substrate and material undergo a state change to form a mutual weld pool. However, as the two methods are very closely related it is important to consider application techniques and best practice involved in laser transmission welding technology.

In [1] an improved method for laser transmission welding of lapped thermoplastic joints is presented. The authors show that for films with thicknesses of less than $100 \mu \mathrm{m}$, the absorption of laser energy is typically less than $20 \%$, presenting a high attenuation length. In addition to this, it is generally found that even moderate laser power can melt or even burn through the upper film layer unless the laser scan speed is high [10]. There is thus a delicate compromise to be had between scan speed, incident power and spot size in order to seal the film layer without damage.

In this work, experiments have been carried out to determine the optimal laser sealing parameters to produce a peel of equivalent strength to that of conventional thermomechanical heat sealing. Package strength is important for post-seal handling and storage, so ball probe and peel strength tests were used to determine puncture resistance of the package and its film peel-ability. It should be noted that the main problems experienced by retailers 
and customers with these sorts of food packages is product leaking out rather than air leakage in, as the cook/chill food content has a short shelf life. In this work, we do not therefore attempt to link peel force to air tightness. It is the burst strength that is more crucial, whereas a high peel strength value does not always guarantee non-leakage.

\section{Background}

Alternatives to the "conventional” hot platen (thermal-pressure) sealing method include laser transmission, ultrasonic and radio-frequency (RF) techniques. Ultrasonic sealing methods are in widespread use in medical and pharmaceutical packaging as well as for food, e.g. in blister packs and for form-fill and seal processes for bags and pouches [11]. The technique is also used in beverage containers for milk, juice, etc. where the card base material is coated with a PP or PE seal layer. Ultrasonic sealing requires pressure to bring the materials into close contact between an anvil and an ultrasound transmitter (horn). Low amplitude frequencies of about $20 \mathrm{kHz}$ (15 - $70 \mathrm{kHz}$ range) are typically used. The vibrational energy absorbed causes localised melting of the materials at the interface, thus forming the weld or seal. The biggest advantage of the technique is that heat sensitive products (e.g. chocolate) are not affected as heating is confined to a very small area within the materials interface. RF sealing is not so well developed at present, although it is claimed that RF methods can seal through contaminants such as sauce, oil and fat. At least one commercial company has produced such a system in a Modified Atmosphere Package (MAP) sealing machine [12].

Laser transmission welding of polymeric materials is in widespread use in many industries including automobile manufacture and food and medical packaging [13]. It involves localized heating at the interface of the two materials to be joined, one of which must be optically transparent to the laser beam and the other highly absorbent. Infra-red absorbing materials are sometimes introduced into the space between the substrates in order to help form the seal, as in the Clearweld (c) process [7, 14-16]. Other work has been carried out in welding of white and transparent thin polypropylene and polyethylene films of low and high density, at speeds of $20 \mathrm{~m} / \mathrm{s}$ using a $\mathrm{CO}_{2}$ laser [17]. Weld strength in the order of 50 to $60 \%$ of material strength was achievable at scan speeds of $10 \mathrm{~m} / \mathrm{s}$. Work by Coelho et al [18] noted decreased laser absorption for films in the order of $100 \mu m$ thickness over thicker samples. For thinner films therefore, a reflective medium beneath the samples was used to produce total absorption. Kurosaki et al [8] used a laser-transparent heat sink on the upper surface of the joint to 
prevent thermal damage to the film layer. Edward et al [19] reported that plastic colouration has a significant effect for absorbance of Nd:YAG laser radiation, ranging from low attenuation (yellow) through to zero transmission (green). Unfortunately little is known about the exact colour of the polymer samples used, but it is clear from the article that material colour has a very low effect on $\mathrm{CO}_{2}$ laser absorbance.

The present authors have already achieved considerable success in the sealing of thicker multilayer films [5]. Upon using a scanning laser, it was found that a more even seal could be produced using a large number of laser passes, at relatively high scan speeds ( $4 \mathrm{~m} / \mathrm{s}$ at $50 \mathrm{~W}$ laser power for 30 passes), when compared to a low speed seal (200mm/s at 7.5W laser power for 3 passes). Low speed laser seals may even melt the material, thus producing a weld instead of a seal, making the product difficult to peel and weakening the film.

Infra-red thermography has been used to monitor the heating and cooling of the plastic materials during and after the laser sealing process [20, 21]. In some of these tests [20], good agreement was obtained between the experimentally measured infra-red temperature distribution and numerically simulated data. It has been suggested [21] that infra-red imaging could be used in this way as part of a condition monitoring system to detect faults in the sealing process.

\section{Materials and apparatus}

The film used was a commercially available, 26 micron thick Esterpeel film, with an amorphous PET sealing layer. Trays were conventional black PET trays, with a clear PET gloss layer applied. The film was stretched over a rectangular frame and kept under tension between in-feed and out-feed rollers, whilst being brought into close contact with the upper surface of the trays. The film feed mechanism was a conventional system obtained directly from a commercial hot platen sealing machine. No direct pressure was used to maintain contact between the film and the tray.

The sealing apparatus used consisted of a Synrad RF-excited $\mathrm{CO}_{2}$ laser, with power regulated by pulse width modulation, using a set-up similar to that of Villagomez et al [22], in conjunction with a General Scanning Inc. galvanometer scanner, having two degrees of freedom in the $(\mathrm{x}, \mathrm{y})$ plane, i.e. the plane of the sealing film. In all cases described, applied 
laser power was $50 \mathrm{~W}$, with a beam spot size of $2.5 \mathrm{~mm}$. The beam mode was close to TEM $\mathrm{M}_{00}$ and the intensity distribution approximately Gaussian. The specification for the laser had a beam propagation ratio $\mathrm{M}^{2}$ of $<1.2$ for mode quality. Laser power was measured at the film surface plane using a conventional power meter. Scan speed was $4.7 \mathrm{~m} / \mathrm{s}$. The calculated energy density or radiant exposure of the laser beam, based on 50W power, spot size of $2.5 \mathrm{~mm}$ and a scan speed of $4.7 \mathrm{~m} / \mathrm{s}$, was $4255 \mathrm{~J} / \mathrm{m}^{2}$ or $0.426 \mathrm{~J} / \mathrm{cm}^{2}$.

The machine system components are shown in Figure 2. Overall system control was accomplished with software written by the authors using a combination of Matlab and C. SCAPS $($ ) software was used to control the laser, which was triggered by an external pulse at the cycle start. The conveyor speed and operation was controlled with an independent PLC, which was triggered also from the overall control (Matlab) computer.

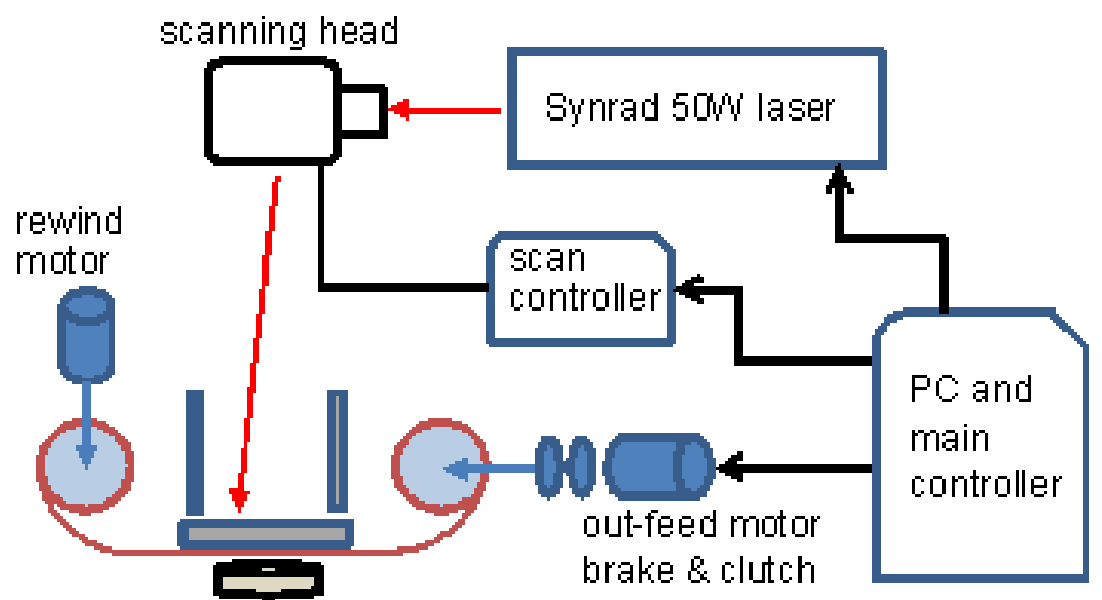

film on rollers supported ower tray

Fig. 2 The laser sealing system, showing integrated computer control of film-feed, laser and scanning optics.

The prototype sealing machine as shown in Figure 3 is based around a modified Packaging Automation PA182 sealing machine, with full film handling capability to bring the pretensioned film into contact with the tray rim. This docks with a scanning laser system which is mounted on lockable castors, and located with machined guides, so that the laser optics line up mechanically with the target area for sealing and cutting. This enables the laser side of the machine to be removed from the area during wash-down (when the food production line is cleaned between successive production runs of product), and to be moved, if necessary, to a different packaging line, ensuring maximum utilisation of the laser system. 


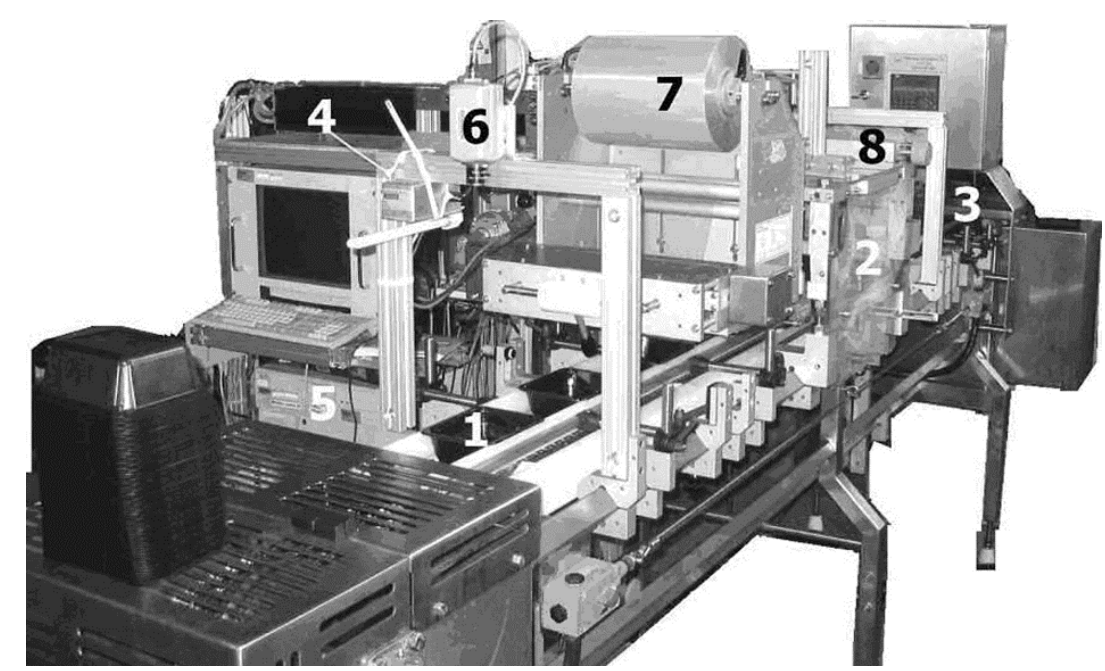

Fig. 3 The laser sealing machine: (1) chain conveyor, (2) polycarbonate enclosure, (3) out-feed side, (4) laser system, (5) computer and controller, (6) CCTV camera, (7) film roll, (8) take-up roller and slipping clutch.

Referring to Figure 3, the tray to be sealed enters the machine on a chain conveyor (1), and is sealed within a polycarbonate enclosure (2) where it remains on the conveyor. The sealed product leaves the machine at (3). The laser system (4) is controlled by an integrated computer (5). The film enters the machine from a roll and travels through the machine in the same direction as the trays (7). Film take-up is affected with a viscous slipping clutch (8), which maintains film tension. Film travel is halted for sealing by an electromagnetic brake and rubber roller at the in-feed side. Once the seal has been completed, the container is freed from the main film web by cutting around the outside of the container with the same laser beam. The waste film web is then advanced onto the take-up roller and the sealed package exits the sealing area on the conveyor at (3).

\section{Experiments}

Benchmarking tests based on peel and burst strength were carried out to associate measurable values with what were perceived by our commercial partners in the food industry to be "good" and "poor” quality seals. A direct comparison could then be made between samples produced using our laser system, and samples produced by our industrial partners using conventional heat sealing. It should be noted that there is not an accepted industry standard for in-line peel quality or burst strength for this type of packaging. The categories of "good" or "poor” were judged by our industrial partners, using criteria representative of the food packaging and retail community. The purpose of the burst tests was to map the mechanical strength of good seals as produced by the conventional process, which would pass leak tests, onto our own process. 


\subsection{Benchmarking tests}

Samples of conventional (non-laser) seals deemed by independent assessment to be good or poor were produced by the industrial partners, without intervention from the research team. Seal quality was controlled by varying the sealing machine parameters such as temperature, dwell time and contact pressure. The purpose of this exercise was to produce samples categorised using product experience and process knowledge. All samples were then subjected to peel tests in our laboratory using a Hounsfield tensometer. In addition to conventional seals, a large number of laser sealed trays were prepared in our labs, to compare with the conventional seal performance.

The peel tests were carried out to verify the desired easy manual opening of the product without resorting to the use of kitchen tools, and to establish the relationship between strength of peel and number of laser passes. When a film tears on peeling, the effort required by a human to maintain the tear is negligible but the pack remains only partly open, creating quality issues. This tends to occur in cases where the seal strength is too high, either for conventional or for laser seals. In this case, the force required by the tensometer to maintain a tear is significantly lower than the starting threshold, and the machine stops automatically. Torn films were therefore regarded as a separate issue and disqualified from the peel strength analysis.

\subsection{Peel tests}

Tray and film were gripped in small jaws in the tensometer (see Figure 4) and peeled apart linearly at a speed not exceeding $80 \mathrm{~mm} / \mathrm{min}$.

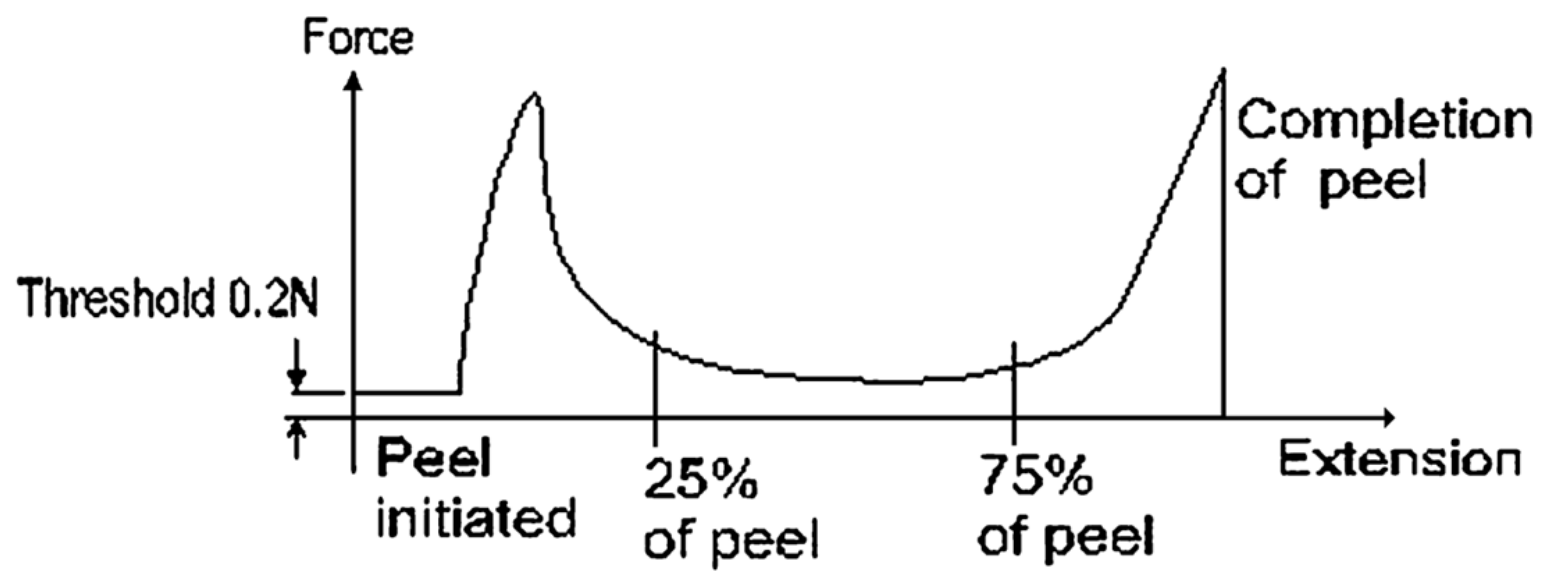

Fig. 4 Peel test overview, showing a typical “bathtub” force/extension curve for the peel process illustrated. 
Readings were taken of applied force (N) vs. extension (mm). Referring to Figure 4, the following results were recorded:

1. Number of samples: The total number of trays successfully peeled for each batch. This number varies because some films may tear instead of peel, in which case that particular peel test was abandoned, for reasons already discussed.

2. Max force $(\mathrm{N})$ : The maximum force encountered during a batch of peel tests.

3. Mean force $(\mathrm{N})$ during $50 \%$ central portion: this is the mean force for all tests between $25 \%$ of peel (gauged by extension from when film tension reaches $0.2 \mathrm{~N}$ ), to $75 \%$ of peel. The maximum extension for percentage calculation was taken as the point where the peel force falls to zero (i.e. completion of peel where tray and film are separated).

4. Mean work done (mJ) during 50\% central portion: This is the product of force and distance (area under the curve) for the same area of the plot as in (3) above.

5. Standard deviation of work done $(\mathrm{mJ})$ during $50 \%$ central portion: This provides an idea of variability of the work required to peel the main part of the seal and was measured across each batch of samples.

\subsection{Ball probe tests}

Ball probe (burst) tests are carried out by driving a 20mm diameter steel ball down on to the film surface near the centre of the sealed container at a speed not exceeding $80 \mathrm{~mm} / \mathrm{min}$. The arrangement for these tests is shown in Figure 5.

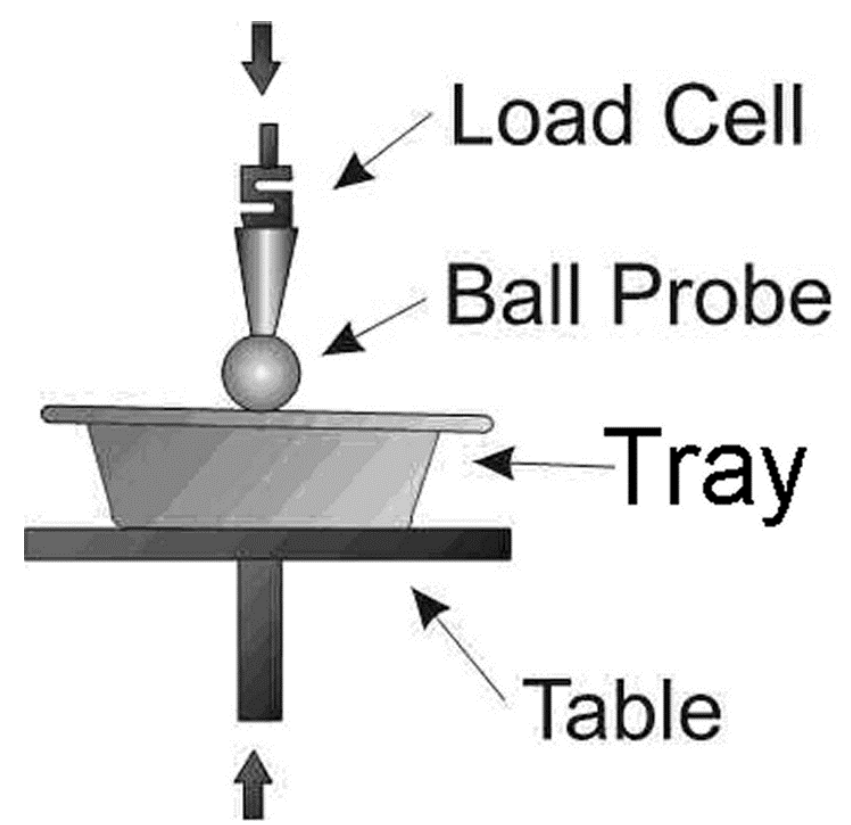

Fig. 5 Ball probe test components and tray/film support conditions. 


\section{Results}

The peel tests from a preliminary set of laser sealed containers are shown in Figure 6. These seals were made with dual concentric seals, at full laser power using 35 passes (around the tray circumference) for each seal at a scan speed of $4.9 \mathrm{~m} / \mathrm{s}$. Initial peel force may be seen to be still relatively high at around 12N, although repeatability of the seals appears good. Figure 7 shows peel results for bad seals for conventionally sealed trays, using a low heater dwell time. Note the much higher peel initiation force. Figure 8 shows the peel characteristics of good conventional seals for comparison.

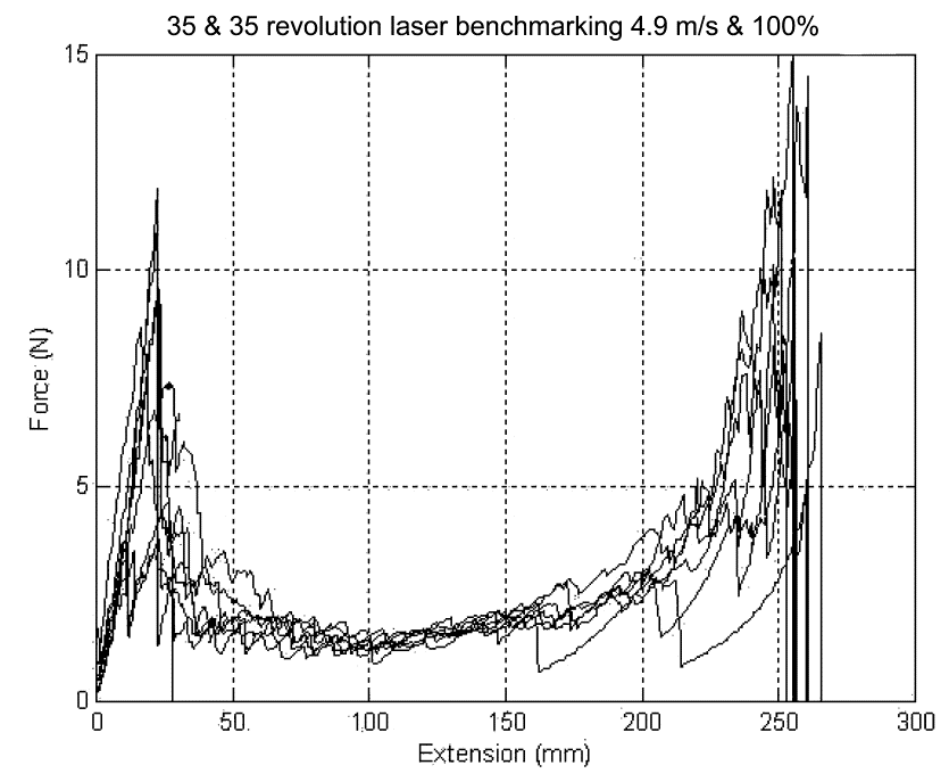

Fig. 6 Peel characteristics of some early dual-concentric (35 pass) laser seals in PET film.

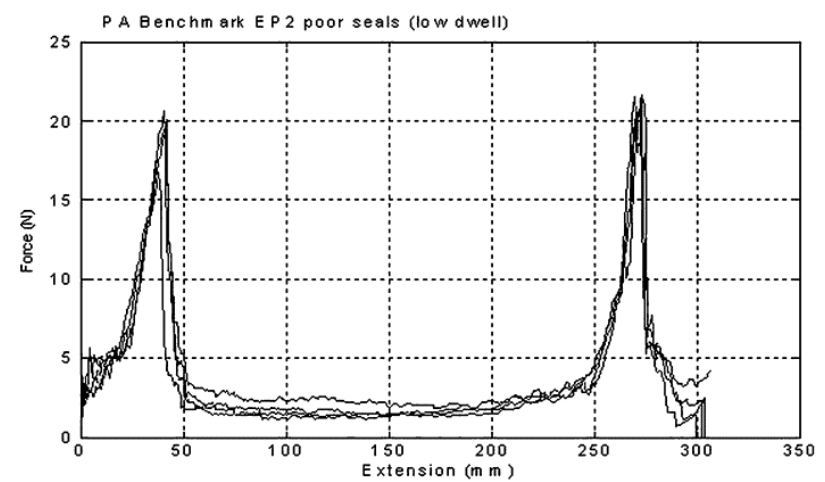

Fig. 7 Peel characteristics of poor quality seals produced using the conventional process with a low dwell time.

The results from analysis of all these tests are presented in Table 1 . The number of valid samples in each category is given in the second column of the table. A dual concentric laser seal was found to give better performance from a very early stage; it can be seen that the laser 
seal made from two concentric circles of 40 passes each is approaching the benchmark good conventional seal in terms of peel strength. Interestingly, the standard deviation in the work done for each peel for the laser sealed trays is significantly lower than that of the good conventional seals, implying that the laser sealing process may be more consistent.

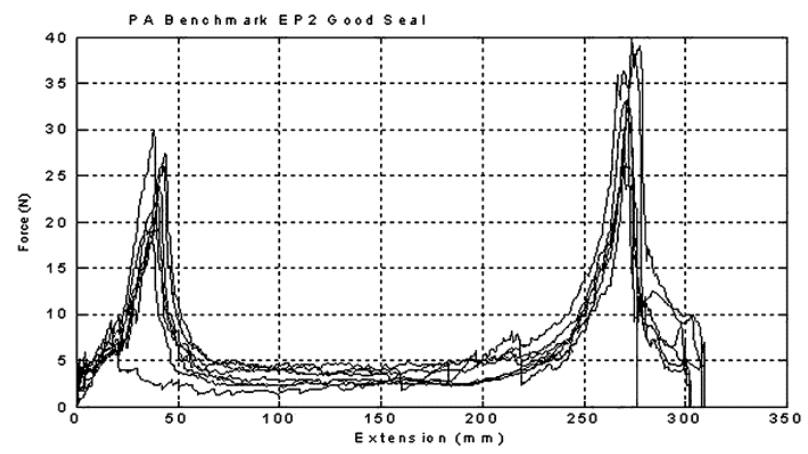

Fig. 8 Peel characteristics of good quality produced using the conventional sealing process (compare peel force peeks with those shown in Figure 7).

\begin{tabular}{|l|l|l|l|l|l|}
\hline $\begin{array}{l}\text { Seal configuration and } \\
\text { assessed quality }\end{array}$ & $\begin{array}{c}\text { No. of } \\
\text { samples }\end{array}$ & $\begin{array}{c}\text { Maximum } \\
\text { force (N) }\end{array}$ & $\begin{array}{c}\text { Mean force } \\
\text { central 50\% (N) }\end{array}$ & $\begin{array}{c}\text { Mean work } \\
\text { done central } \\
50 \%(\mathrm{~mJ})\end{array}$ & $\begin{array}{c}\text { SD work } \\
\text { done central } \\
50 \%(\mathrm{~mJ})\end{array}$ \\
\hline $\begin{array}{l}\text { Conventional (bad) } \\
\text { Low dwell }\end{array}$ & 4 & 21.60 & 1.76 & 270 & 40 \\
Low temp & 5 & 7.43 & 0.67 & 90 & 10 \\
Low pressure & 4 & 25.40 & 1.90 & 290 & 50 \\
\hline Conventional (good) & 8 & 40.00 & 3.41 & 510 & 160 \\
\hline Laser (dual & 5 & 14.66 & 2.26 & 300 & 30 \\
concentric seal) & & & & & \\
\hline
\end{tabular}

Table 1 Comparison of conventional and laser seal performance. The dual concentric laser seal was done with 40 passes at $100 \%$ power, with a scan speed of $4.9 \mathrm{~m} / \mathrm{s}$

The next step was to attempt to increase seal strength to that of the conventional process produced by the industrial partners. Film breakage at more than 40 passes of the laser became a constant problem, since a circular laser seal has greater peel force, whereas for the conventional process, trays had a more gradual 'lead in' via sealing over the tray flanges. The outer of the two laser seals was modified to encircle the outer edge of the tray, providing a more gradual 'lead in' at the beginning of peel. Note that for these curves only the flange where the peel is initiated has the modified seal path, both paths still being circular at peel 
exit, hence the increase in force for the final peel. The modified paths for these dual seals are shown in Figure 9. The dual concentric seal was achieved with 45 and then 40 passes of the laser beam, allowing the seal to cool to room temperature before handling.

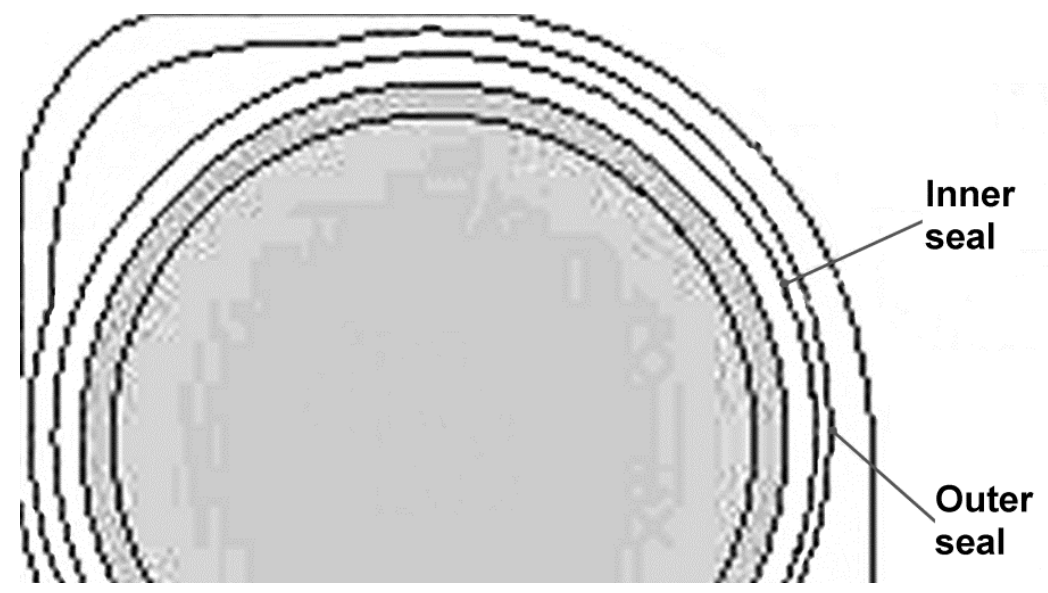

Fig. 9 Layout of dual concentric laser seals on the periphery of a circular food container. Note the extended pathway of the outer seal in order to initiate easier peeling.

Film breakage during peel was also present for a dual-concentric seal using 40 laser passes, with the modified seal path, making it difficult to compare laser sealed trays with conventionally sealed trays. A number of trays were frozen as soon as they had been sealed, in order to effect rapid cooling. The difference in peel smoothness can be clearly seen in Figure 11, when compared with the control batch (Figure 10), which was left at room temperature.

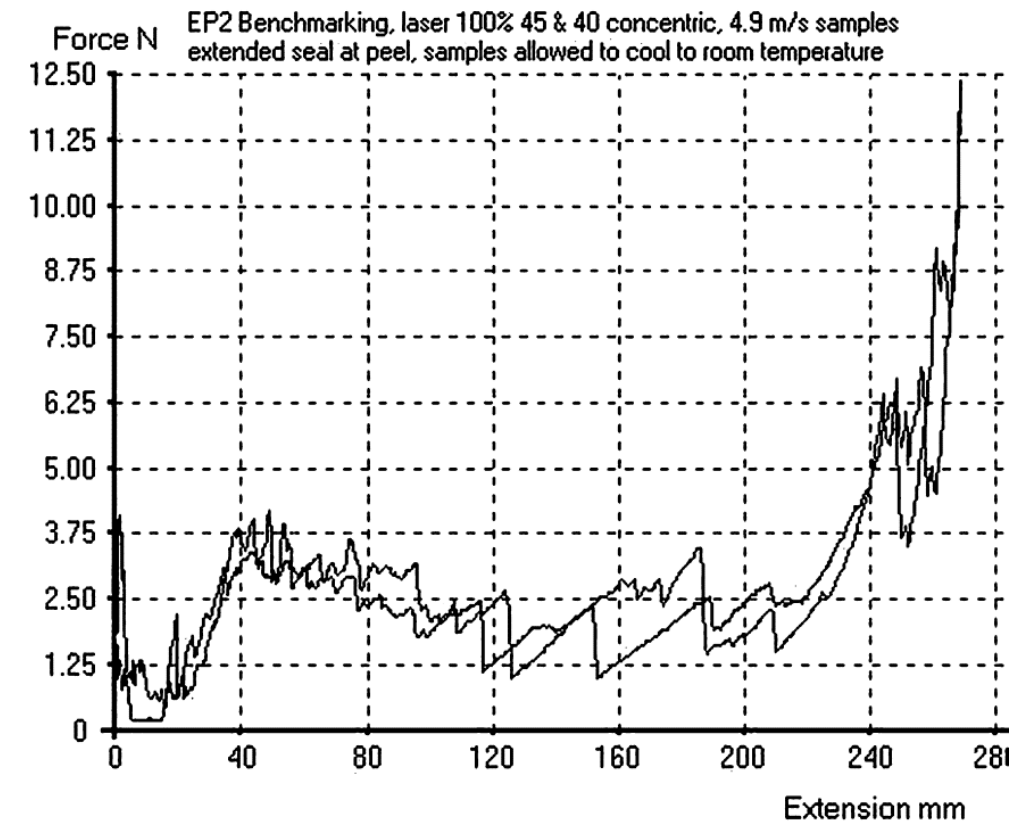

Fig. 10 Peel characteristics of dual concentric (45 and 40 pass) laser seals, allowed to cool to room temperature after sealing and before handling. 


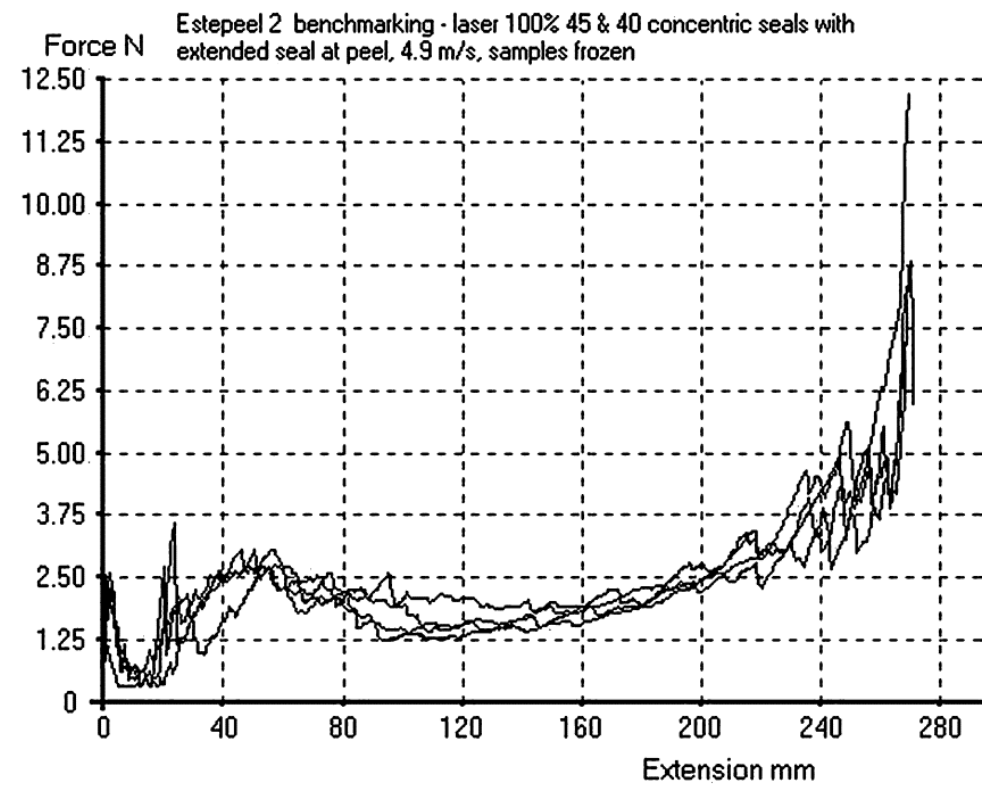

Fig. 11 Peel characteristics of dual concentric (45 and 40 pass) laser seals, frozen after sealing and before handling.

\subsection{Triple concentric seals}

In order to further improve seal performance, a triple seal was used, as shown in Figure 12, with 35 passes of the laser beam on each seal. Again, the outer seal had a modified path to initiate an easier peel. This combination allowed a stronger seal without heating the film to the point where adjacent areas may be weakened, causing film tear on peeling. Table 2 shows that with increased seal area, greater peel strength is possible if required, through the use of a triple concentric laser seal.

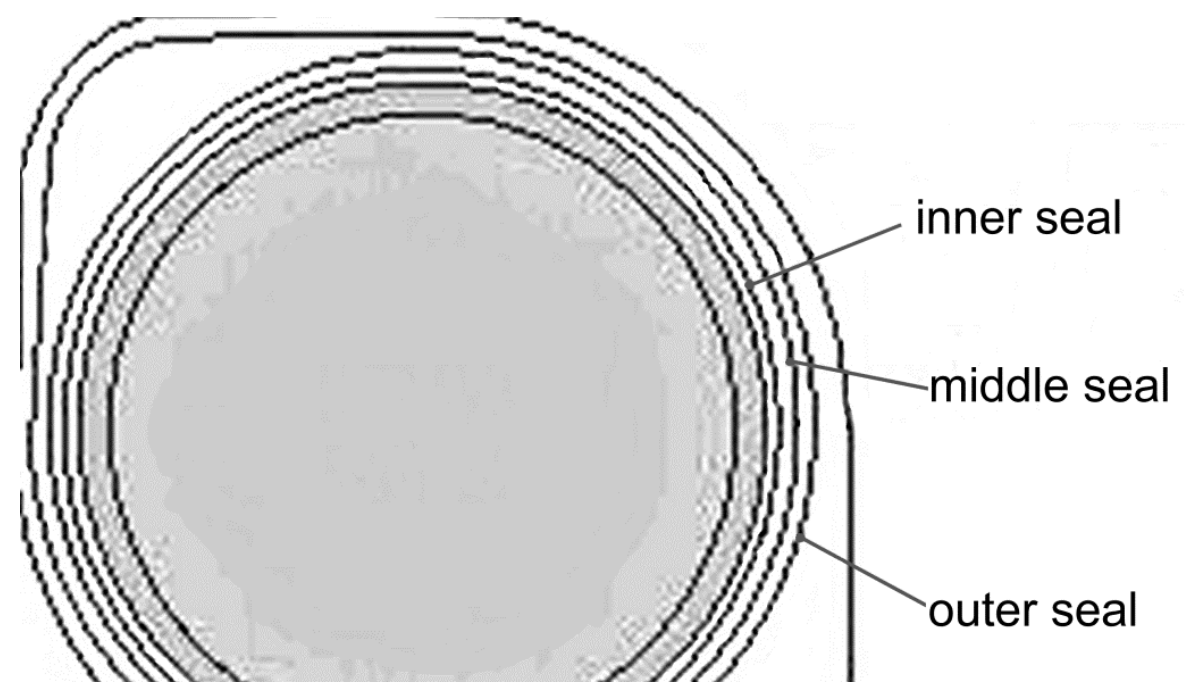

Fig. 12 Layout of triple concentric laser seals on the periphery of a circular food container. Note the extended pathway of the outer seal in order to initiate easier peeling. 


\begin{tabular}{|l|l|l|l|l|l|}
\hline $\begin{array}{l}\text { Seal configuration and } \\
\text { assessed quality }\end{array}$ & $\begin{array}{c}\text { No. of } \\
\text { samples }\end{array}$ & $\begin{array}{c}\text { Maximum } \\
\text { force (N) }\end{array}$ & $\begin{array}{c}\text { Mean force } \\
\text { central 50\% (N) }\end{array}$ & $\begin{array}{c}\text { Mean work } \\
\text { done central } \\
50 \%(\mathrm{~mJ})\end{array}$ & $\begin{array}{c}\text { SD work } \\
\text { done central } \\
50 \%(\mathrm{~mJ})\end{array}$ \\
\hline $\begin{array}{l}\text { Conventional (good) } \\
\text { Laser (dual } \\
\text { concentric seal) }\end{array}$ & 5 & 40.00 & 3.41 & 510 & 160 \\
\hline $\begin{array}{l}\text { Laser (triple } \\
\text { concentric seal) }\end{array}$ & 4 & 14.66 & 2.26 & 300 & 30 \\
\hline
\end{tabular}

Table 2 Performance of triple concentric seals. The dual concentric laser seal was done with 40 passes at $100 \%$ power, with a scan speed of $4.9 \mathrm{~m} / \mathrm{s}$. The triple laser seal was done with 35 passes at $100 \%$ power, with a scan speed of $4.9 \mathrm{~m} / \mathrm{s}$.

\subsection{Ball probes tests}

A dual concentric and triple concentric laser seal may be adjusted to produce slightly higher bursting strength, yet peel at a slightly lower force than for the conventional process. The set of curves in Figure 13 shows the result of ball probe testing for laser sealed containers. These samples were produced with a dual concentric laser seal of 40 passes on each seal, which produces a tray with a slightly lower peel force (i.e. enhanced peel-ability) when compared to the conventional process. Results are summarised in Table 3.

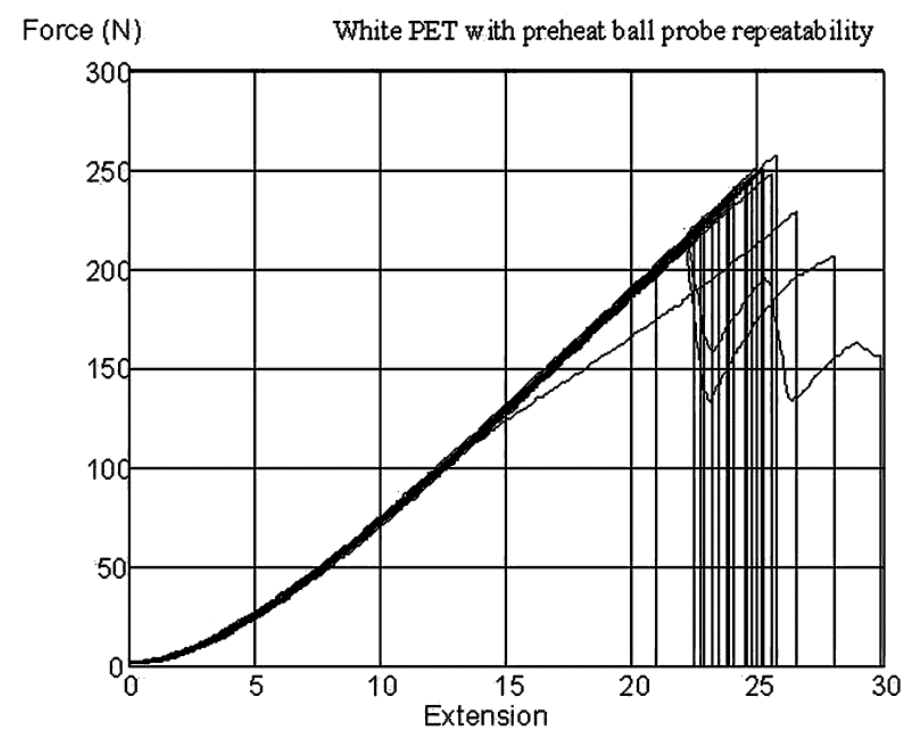

Fig. 13 Ball probe repeatability test results for dual concentric laser sealed containers. 


\begin{tabular}{|l|l|l|l|l|}
\hline \multicolumn{1}{|c|}{$\begin{array}{c}\text { Seal configuration and } \\
\text { assessed quality }\end{array}$} & $\begin{array}{l}\text { No. of } \\
\text { samples }\end{array}$ & $\begin{array}{l}\text { Maximum } \\
\text { force }(\mathrm{N})\end{array}$ & $\begin{array}{l}\text { Mean work done } \\
\text { central 50\% }(\mathrm{mJ})\end{array}$ & $\begin{array}{l}\text { SD work done } \\
\text { central 50\% (mJ) }\end{array}$ \\
\hline Conventional (good) & 7 & 242.0 & 860 & 250 \\
\hline Laser (good) & 28 & 256.4 & 1190 & 220 \\
\hline
\end{tabular}

Table 3 Ball probe tests for conventional and laser seals

\section{Conclusions}

We have demonstrated that it is possible with laser transmission techniques, to produce a food tray seal in very thin film material that has significantly enhanced peel-ability when compared to the conventional process, with a stronger bursting strength. We believe that this is due in part to film weakening in the conventional process, where the pressure applied to the seal produces slight thinning of the film in the seal area. Micrograph images (see example image in figure 14) obtained from sectioned specimens of conventionally sealed trays during the work described in [6] showed that material is squeezed away from the sealing zone due to mechanical pressure of the tooling platen. The partly attached, multi-layer film in Figure 14 can be seen to have a much greater free thickness (T1) than after pressure sealing to the tray substrate (T2). This does not happen with our laser seals where there is little or no contact force. It also appears from this pervious work, and from the current tests on single layer films, that the laser sealing process is eminently controllable, with a predictable result in terms of the relationship between energy input to the seal, and the resultant seal strength.

It should be noted that, given the relatively small number of samples tested, the results provided cannot be said to be statistically significant. However, we are presenting here the evolution of a process and the evidence so far shows clearly that effective laser sealing of thin polymer films is possible, with all the concomitant advantages it can bring to the industrial process at which it is aimed. Further testing is needed to produce statistically valid samples and to establish thoroughly how the process parameters (laser power, beam size, scan speed and number of scans) relate to measureable seal quality indicators, particularly peel and burst strength.

A process has been demonstrated which, using a beam steered $\mathrm{CO}_{2}$ laser, removes the need for conventional tooling, greatly reducing the necessary machine stiffness, weight and cost. 


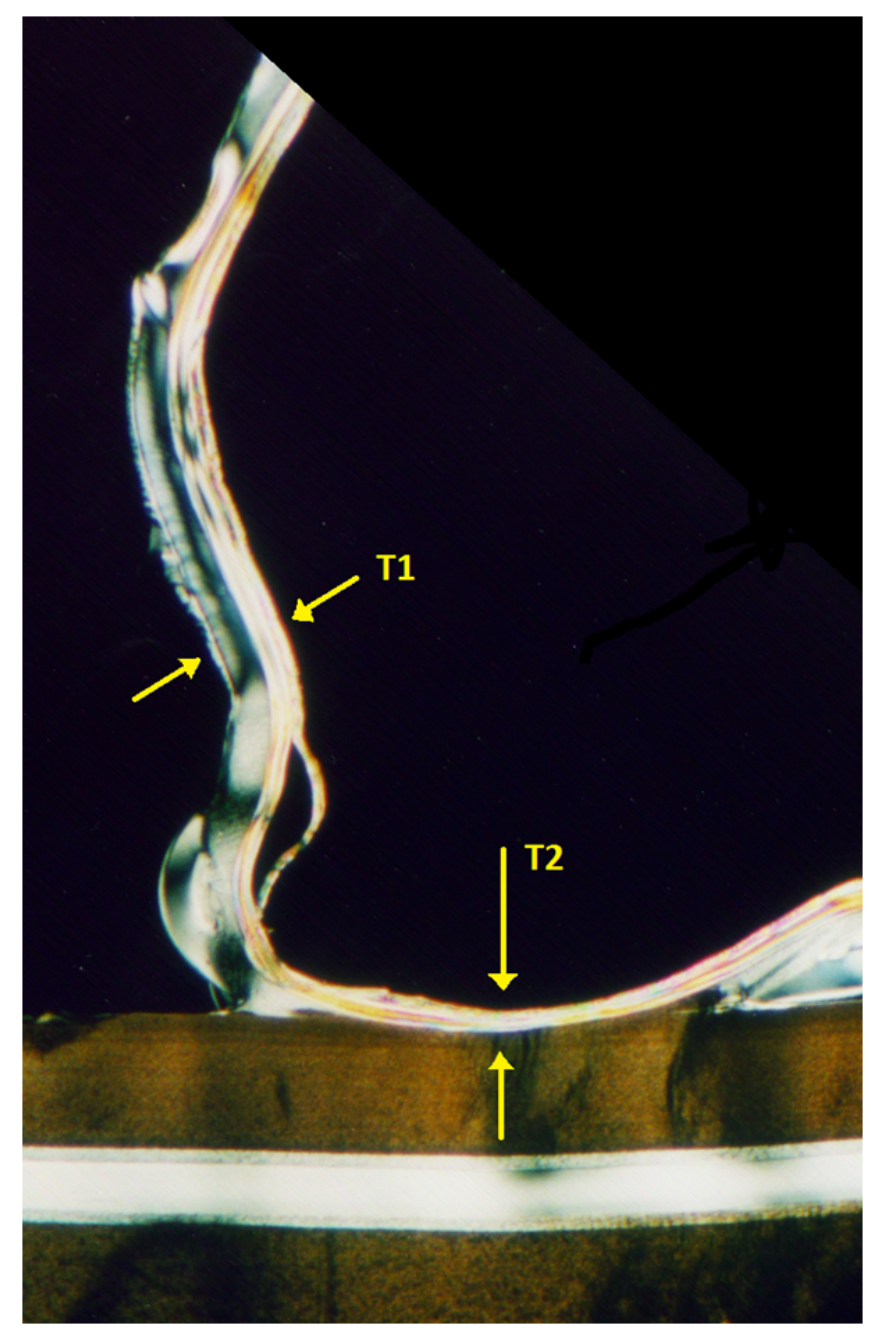

Fig. 14 Micrograph of section of specimen with conventional thermal-pressure seal; T1 is the original film thickness; T2 is thickness after pressure sealing onto tray.

Our prototype machine uses only a fraction of the components of the conventional PA 182 system from which it was constructed. The choice of laser power and scan speed is important for producing a good seal, however the effect of material thermal time constants must not be ignored. Whilst the upper limit of processing speed for laser sealing of polymer film has yet to be defined, it is clear from our tests and from subsequent on-line trials in one of our partner's factories, that material choice is important for higher speeds, as well as careful choice of sealing strategy, if the components of the film are to remain undamaged. The present limitations in sealing speed are mostly due to poor absorption of the $\mathrm{CO}_{2}$ laser wavelength. By choosing a combination food safe material with a laser wavelength more suited to its absorption windows, faster scan speeds should be possible. At the time of writing, container throughput from our prototype system remains limited to only around 1215 packs per minute. 
However, there is no reason why a laser-based system could not eventually match or exceed the conventional process in cycle speed. Present production rates of 60 trays per minute are only possible with conventional methods using multi-impression sealing heads, where 4, 6 or 8 trays are sealed in one cycle. Reduction in cycle times for the laser method would be greatly assisted by the adoption of sealing strategies using multiple scanning paths from a single, more powerful laser, allowing seal quality repeatability to be maintained at each individual tray location. Furthermore, matching of the laser wavelength to absorption properties of carefully selected, food safe substrate materials would further improve the machine efficiency as well as individual cycle times.

\section{Acknowledgements}

The authors would like to thank the project industrial partners: Packaging Automation Ltd, GSI Lumonics Ltd, The Recipe Dish Company Ltd, FFP Packaging Solutions Ltd, and RPC Containers Ltd. The project was funded under the DEFRA/LINK Programme Code AFM114, “Intelligent Package Sealing and Inspection System for Semi-rigid Food Containers.” 


\section{References}

[1] J.M.P. Coelho, M.A. Abreu, F.C. Rodrigues, Modeling CO2 laser radiation transmission lap welding of thermoplastic films: energy balance approximation Optical Engineering, 46 (2007).

[2] W. Michaeli, W.-M. Hoffmann, E. Haberstroh, Laser welding of transparent plastics by means of the intermediate film method, in: 66th Annual Technical Conference of the Society of Plastics Engineers (ANTEC 2008), Society of Plastics Engineers, 14 Fairfield Drive - P.O. Box 403, Brookfield, CT 06804-0403, United States, Milwaukee, WI, United States, 2008, pp. 1268-1272.

[3] T. Sakai, H. Imai, H. Yokoya, H. Nishida, N. Hamada, Laser heat sealing of the polymer coated steel sheet in: 26th International Congress on Applications of Lasers and ElectroOptics, ICALEO 2007, Laser Institute of America, Orlando, FL, United States, 2007.

[4] N. Brown, D. Kerr, M.R. Jackson, R.M. Parkin, Laser welding of thin polymer films to container substrates for aseptic packaging, Optics \& Laser Technology, 32 (2000) 139-146.

[5] N. Brown, F. Shi, D. Kerr, M.R. Jackson, R.M. Parkin, CO2 laser processing of packaging films including multi-layer laminates containing silicon oxide and ethylene vinyl alcohol barrier layers, in: R.M. Parkin, A. Al-Habaibeh, M.R. Jackson (Eds.) International Conference on Mechatronics (ICOM) 2003, Professional Engineering Publishing, Loughborough, UK, 2003, pp. 383-388.

[6] N. Brown, F. Shi, D. Kerr, M.R. Jackson, R.M. Parkin, $\mathrm{CO}_{2}$ Laser Processing of Multilayer Packaging Films, Proc. I MECH E Part I Journal of Systems \& Control Engineering, 219 (2005) 231-237.

[7] N. Amanat, C. Chaminade, J. Grace, D.R. McKenzie, N.L. James, Transmission laser welding of amorphous and semi-crystalline poly-ether-ether-ketone for applications in the medical device industry, MATERIALS \& DESIGN, 31 (2010) 4823-4830.

[8] Y. Kurosaki, T. Matayoshi, K. Sato, A novel CO2 laser welding of plastics using a transparent solid heat sink without causing thermal damage, in: ICALEO 2006 - 25th International Congress on Applications of Laser and Electro-Optics, Laser Institute of America, Scottsdale, AZ, United States, 2006.

[9] FFP Packaging Solutions ltd, Esterpeel heat sealable lidding films, http://www.ffppkg.co.uk/pdfs/Esterpeel1.pdf, accessed 30 March 2012.

[10] T. Matayoshi, K. Sato, Y. Kurosaki, Overlap Welding Of Thermoplastic Parts Without Causing Surface Thermal Damage By Using A CO2 Laser, in: 61st Annual Technical Conference - ANTEC, Society of Plastics Engineers, Nashville, TN, United States, 2003, pp. 1121-1125.

[11] S. Engelmann, Ultrasonic sealing and cutting in thermoforming, in: 67th Annual Technical Conference of the Society of Plastic's Engineers, Society of Plastics Engineers, Brookfield, CT, USA, 2009, pp. 834-836.

[12] L. Searby, MAP Lines Redrawn, Packaging News, December (2006) 47-48.

[13] N. Amanat, N.L. James, D.R. McKenzie, Welding methods for joining thermoplastic polymers for the hermetic enclosure of medical devices, Medical Engineering and Physics, 32 (2010) 690-699. 
[14] Gentex Corporation, Clearweld Concept, http://www.clearweld.com/concept.html, accessed 30 March2012.

[15] N.M. Woosman, L.P. Frieder, Clearweld: welding of clear, coloured, or opaque thermoplastics, Proc. IMechE Part D: Journal of Automobile Engineering, 219 (2005) 10691074.

[16] I. Jones, Laser welding for plastic components, Assembly Automation, 22 (2002) 129135.

[17] J.P. Coelho, M.A. Abreu, M.C. Pires, High-speed laser welding of plastic films, Optics \& Lasers in Engineering, 34 (2000) 385-395.

[18] J.P. Coelho, M.A. Abreu, M.C. Pires, Laser cutting of superposed plastic films, in: T.J.G. Corcoran (Ed.) International Conference on Lasers 98, STS Press, Tucson, AZ, USA, 1998, pp. 661 - 665.

[19] B.P. Edward, A. Sheshnev, E. Shulzinger, Y. Bormashenko, A. Katzir, IR laser radiation induced changes in the IR absorption spectra of thermoplastic and thermosetting polymers., Journal of Optics A: Pure and Applied Optics, 3 (2001) 229 - 235.

[20] M. Speka, S. Matteï, M. Pilloz, M. Ilie, The infrared thermography control of the laser welding of amorphous polymers, NDT \& E International, 41 (2008) 178-183.

[21] A. Al-Habaibeh, F. Shi, N. Brown, D. Kerr, M.R. Jackson, R.M. Parkin, A novel approach for quality control system using sensor fusion of infrared and visual image processing for laser sealing of food containers, Measurement Science \& Technology, 15 (2004) 1995-2000.

[22] R. Villagomez, R. Valenzuela, R. Camacho-Mesa, Laser welding of Nylon thin films using a pulsed CO2 waveguide laser, in: E. Rosas, N. Arzate, I. Torres, J. Sumaya (Eds.) 8th Symposium Optics in Industry, SPIE, Toluca de Lerdo, Mexico, 2011. 